\title{
Correspondence
}

\section{Biased touching of the editorial tiller}

Sir,

I was saddened to find that your redrafted instructions to authors ${ }^{1}$ confirm that you continue to allow authors of 'negative trials' a mere 500 words to introduce and state their hypotheses, give an adequate description of their methods and results, and state their conclusions. Although you do not define the term negative trial, presumably you use it to refer to studies in which no statistically significant differences between treatments have been shown.

This biased touching of the editorial tiller has two serious implications. Firstly, it discourages submission of statistically powerful treatment comparisons in which no statistically significant differences are observed. Secondly, because statistically significant differences observed in small trials tend to overestimate true treatment differences, it actively fosters such overestimates in the material you make available to your readers.

It has been suggested ${ }^{2}$ that the onus of ensuring appropriate design of clinical trials should be on the editors of scientific journals. Over recent years, there have been several publications detailing criteria for designing and reporting clinical trials, some of them directed specifically at journal editors. ${ }^{34}$ I hope you may consider adopting an editorial policy which places more emphasis on sound research methods than on statistical significance.

Meanwhile if there are investigators among your readers who at any time over the past 30 years have completed perinatal trials which have never reached publication (either because the results were 'negative' or for any other reason), they are invited to send brief details for incorporation in the National Perinatal Epidemiology Unit Register of Controlled Trials in Perinatal Medicine. In collaboration with colleagues in North America, we wish to use this information in an attempt to learn more about the 'selective publication bias'.

\section{References}

1 Instructions to authors. Arch Dis Child 1985;60:90-1.

2 Spodick DH. The end of clinical freedom. Br Med J 1983;287: 1885.

${ }^{3}$ Zelen M. Guidelines for publishing papers on cancer clinical trials: responsible for editors and authors. J Clin Oncol 1983;1:164-9.

${ }^{4}$ Mosteller F, Gilbert JP, McPeek B. Reporting standards and research strategies for controlled trials: agenda for the editor. Controlled Clin Trials 1980;1:37-58.

Iain Chalmers

National Perinatal Epidemiology Unit, Radcliffe Infirmary, Oxford $O X 26 H E$

Dr Chalmers is undoubtedly correct in pointing out the selective bias that exists as a result of international medical journals being more willing to publish papers that show a new positive result than those reporting trials yielding a negative result. It was because of this bias that we decided, as a matter of policy, to try and include more 'negative trials' providing that they were based on a reasonable hypothesis. Since space is at a premium, however, and we receive many more good original articles than we are able to publish we ask that the length of these papers be reasonably brief.

In relation to our journal the position is not quite as bleak as Dr Chalmers suggests. Much will depend upon the nature of the trial and the hypothesis on which it is based. For instance, if we received a long paper reporting a well conducted trial which showed that the vitamin status of mothers at the time of conception was completely irrelevant to the occurrence of neural tube defects in their babies we would wish to publish that in full-because it is an important, negative result contrary to many present beliefs. If, however, we received a paper showing that the mother's smoking habits during pregnancy were unrelated to the prevalence of bed wetting in her child at school age we would be unlikely to wish to publish that in full, however large or carefully done the study. Thus the interest and strength of the hypothesis on which the study is based is all-important. Between the two extremes I have cited come a number of negative results trials based on reasonable, if somewhat tenuous hypotheses reporting careful work. At present these rarely achieve publication anywhere (which is not surprising because most of them are very boring), yet it is these that we would wish to report in some way. Therefore we offer the opportunity for such studies to be reported briefly as short reports in our journal, if only to prevent other people from embarking along that particular path. In our notice to contributors we suggest that 'a short report of not more than 500 words is more likely to gain acceptance than a longer report'. Those who are interested in the study may communicate with the authors for more detailed information. Ed.

\section{Alcohol and the fetus}

Sir,

I read with interest the annotation by Smithells and Smith ${ }^{1}$. It seems to be generally implied that the alcoholic mother is the sole cause of the fetal alcohol syndrome, and so should be the one that abstains from alcohol during pregnancy. In some children whose clinical picture matches perfectly that of fetal alcohol syndrome, I have been unable to obtain a definite history of alcohol abuse by the mother; though in other cases, such as a mother who is a barmaid with cirrhosis, it is obvious.

I recently reviewed a child who had all the features of the syndrome. She was small for gestation, and at 11 months weighed $6.1 \mathrm{~kg}$. She was an active, sociable child with a small central cleft and a systolic heart murmur. She 
had the typical facial appearance with a small upturned nose, long philtrum, a rather large mouth with a thin upper lip, low set ears, and epicanthic folds. Mother had smoked between 20 and 40 cigarettes a day during pregnancy but gave no definite history of taking alcohol. When I discussed this with her she said, with conviction that she did not like alcohol and she stuck to soft drinks. She added, 'but it's the child's father who drinks, in fact the only time he visited the child he was drunk'. She said it was a family joke that they thought that the child's red nose was due to her father being an alcoholic.

Perhaps if we also looked into the alcoholic intake of the sperm we might have better understanding of the syndrome. I understand from my senior house officer that Carthage recognised that it was a bad thing to take wine on the nuptial night. ${ }^{2}$

EILEEN E HILL East Birmingham Hospital, Birmingham B9 5ST

Professor Smithells and Dr Smith comment:

Dr Hill is not the first to report the features of fetal alcohol syndrome in the offspring of a mother who denies taking alcohol. Hanson, Streissguth, and $\mathrm{Smith}^{3}$ identified 11 newborns who were 'abnormal with features of FAS'. Little or no alcohol had been consumed by two of the mothers in the month before pregnancy and by four during the first five months of pregnancy. It is therefore at least possible that there are phenocopies of fetal alcohol syndrome not associated with alcohol. Hence our caution in subscribing to the notion of a specific syndrome.

Histories of alcohol intake are notoriously inaccurate if routine questions are used ${ }^{4}$ and we must all judge the reliability of any information given to us by parents. Even after fairly intensive questioning, about half the mothers of thalidomide damaged children denied having taken the drug, although the analogy with alcohol is not particularly close.

The role of the drunken father is even more difficult to study. In Carthage and in Greece the wedding reception was indeed 'dry', 5 and the lameness of the god Vulcan was attributed to his having been sired by Jupiter when in a drunken stupor. ${ }^{6}$ The old testament was content to advise against alcohol during pregnancy (Judges 13:7). We have no great difficulty envisaging an inebriated sperm weaving its way up to the fallopian tube and, with one last supreme lurch, penetrating a chaste and unsuspecting egg. We have more difficulty believing that the dose of ethanol thereby delivered could have a profound influence on fetal growth for nine months and on embryological events still weeks away.

But we are men, and Dr Hill is not!

\footnotetext{
References

' Smithells RW, Smith IJ. Alcohol and the fetus. Arch Dis Child 1984;59:1113-4.

2 Jones KL, Smith DW. Recognition of the fetal alcohol syndrome in early infancy. Lancet 1973;ii:999-1001.

${ }^{3}$ Hanson JW, Streissguth AP, Smith DW. Effects of moderate
}

alcohol consumption during pregnancy on fetal growth and morphogenesis. J Pediatr 1978;92:457-60.

${ }^{4}$ Barrison IG, Viola L, Murray-Lyon IM. Do housemen take an adequate drinking history. Br Med $J$ 1980;ii:1040.

${ }^{5}$ Haggard HW, Jellinek EM. Alcohol explored. Doubleday Doran, New York. 1942.

${ }^{6}$ Rasmussen BB, Christensen N. Alkohol og fosterskader. Ugeskrift for Laeger (Copenhagen). 1978;140:282-4.

\section{High and conventional ventilation rates in the newborn}

Sir,

Dr Field and colleagues' interesting study ${ }^{1}$ on the effect of mechanical ventilation at rates of less than 50 and of $100 /$ minute on oxygenation and spontaneous respiration prompts three questions.

(1) What flow rates were used during the studies and were they altered in the transition from slower to more rapid rates in order to maintain the other ventilator settings constant?

(2) How can the authors exclude the possibility that the changes in oxygenation seen during transition from slow to fast rates were not a reflection of changes in mean airway pressure? For instance if flow was increased at fast rates, a consequent increase in mean airway pressure could account for all or part of the increased oxygenation documented in six infants.

(3) How many instances have the authors documented of the pattern of reflex expiratory effort against ventilator inflation which they cited ${ }^{2}$ and can they confirm that such babies develop pneumothoraces?

\section{W TaRnow-Mordi and A Wilkinson John Radcliffe Hospital, Oxford $O X 3$ 9DG}

\section{Dr Field and Professor Milner comment:}

We thank Drs Tarnow-Mordi and Wilkinson for their comments and, in answer to the points they have raised, we are able to add the following information;

(1) Ventilator flow rates were adjusted at the start of each study to compensate for the loss of bias flow through the pneumotachograph, and then remained constant for the duration of the investigation. They were approximately 6 litres/minute.

(2) We have looked formally at the effect of fast ventilator rates on mean airway pressure and found that the Draeger Babylog ventilator produces no significant variation in mean airways pressure when used over the range of ventilator rates employed in this study. ${ }^{3}$ We confirmed this finding in the babies reported in this study.

Some workers feel that the use of fast ventilator rates leads to an inadvertent positive end expiratory pressure within the lungs which affects gaseous exchange. Evidence in support of this phenomenon has been provided mainly by in vitro ${ }^{4}$ or animal studies. ${ }^{5}$ All our infants were in the acute phase of idiopathic respiratory distress syndrome and 